\title{
Terrier Breed
}

National Cancer Institute

\section{Source}

National Cancer Institute. Terrier Breed. NCI Thesaurus. Code C53697.

The Terrier Group includes energetic dogs whose sizes range from fairly small, as in the Norfolk, Cairn or West Highland White Terrier, to the grand Airedale Terrier. Terriers typically have little tolerance for other animals, including other dogs and tend to have a distinctive terrier personality. Their ancestors were bred to hunt and kill vermin. Most terriers have wiry coats that require special grooming known as stripping in order to maintain a characteristic appearance. 